\title{
UPOREDNA ANALIZA PRISTUPA 3D MODELOVANJU I OPTIMIZACIJI MODELA NAMES̆TAJA
}

\section{COMPARATIVE ANALYSIS OF 3D MODELING AND OPTIMIZATION OF FURNITURE MODELS}

\section{Radiša Pavićević, Fakultet tehničkih nauka, Novi Sad}

\section{Oblast -ARHITEKTURA I URBANIZAM}

Kratak sadržaj - U radu je obuhvaćen proces modelovanja $i$ optimizacije modela nameštaja kroz dva različita programa. Uporednom analizom primenjenih metoda izvedeni su zaključci o njihovim prednostima $i$ manama kao i o tome koje od njih su najpovoljnije za dato istraživanje.

Ključne reči: Modelovanje, optimizacija, uporedna analiza

Abstract - This research covers the process of modeling and optimization of model trough two different programs. By comparative analysis of the applied methods, conclusions were drawn about their advantages and disadvantages as well as which of them are the most suitable for given research.

Keywords: Modeling, optimization, comparative analysis

\section{UVOD}

Postoje mnogobrojni programi koji omogućavaju modelovanje i renderovanje različitog kvaliteta, međutim prednost imaju oni koji se mogu povezati sa drugim softverom pritom dajući mogućnost direktnog plasiranja modela na internet i kreiranja podešavanja koje korisnik može koristiti. Takvi su „3DS Max” i „Blender” koji spajanjem sa drugim programima, pružaju velike mogućnosti pri modelovanju i manipulaciji završnog modela kada se radi o njegovim teksturama i bojama.

Ovaj rad se zasniva na istraživanju kvaliteta modela i njegove optimizacije u pomenutim programima gde se ispituje koji od načina daje najbolje finalne rezultate, pri čemu će kriterijumi za procenu boljeg modela biti navedeni kasnije u radu.

\section{MODELOVANJE}

Modelovanje se u oba programa obavlja po ugledu na isti model stolice iz kolekcije Orren Ellis koji je unapred odabran (slika 1), a zatim se finalni rezultati uporede prema parametrima koji su takođe unapred određeni.

Ti parametri su: kompleksnost i vreme potrebno za izradu modela, da li geometija finalnog modela zadovoljava potrebu za realističnim prikazom stolice i koliko poligona i verteksa ima finalni model.

\section{NAPOMENA:}

Ovaj rad je proistekao iz master rada čiji mentor je bila dr Vesna Stojaković, van.prof.

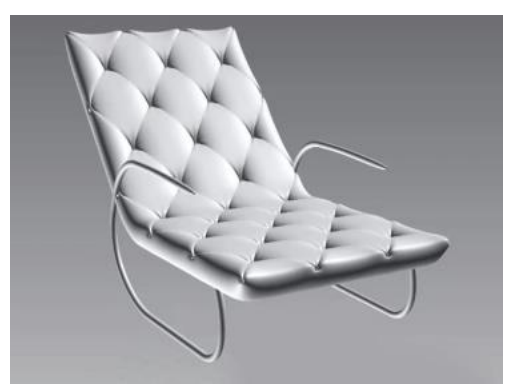

Slika 1. Ugledni model stolice iz kolekcije Orren Ellis

Cilj je odrediti koja je od primenjenih metoda modelovanja daje najboji finalni rezultat koji bi se koristio pri izradi trodimenzionalne prezentacije.

\subsection{Modelovanje stolice korišćenjem 3DS Max-a}

Ispitani pristupi za modelovanje u 3DS Max-u su takozvani polygon modeling, odnosno modelovanje uz korišćenje osnovnih geometrijskih oblika i NURBS modelovanje, koje se zasniva na pravljenju oblika uz pomoć krivih.

\subsubsection{Polygon modeling}

Polygon modeling se zasniva na modelovanju osnovnih geometrijskih tela koja se kasnije spajaju, seku i preklapaju čineći složenije modele.

Za zadati ugledni primer (slika 1) može se utvrditi da se sastoji od geometrije koja čini sedište i naslon stolice (kubus), i one koja čini šipke za njeno oslanjanje (cilindri).

Prilikom procesa modelovanja segmenta koji čini sedište $\mathrm{i}$ naslon su primenjeni modifajeri kako bi se dobila tekstura tekstilne obloge stolice.

Proces se sastoji od podele box-a i manipulacije njegovih verteksa i edževa uz pomoć opcije extrude. $\mathrm{Na}$ tako dobijen model je primenjen modifajer Turbo Smooth čija je funkcija da zaobli model. Finalni oblik ovog segmenta je dobijen savijanjem uz pomoć opcije bend pri čemu su jasno određeni delovi stolice koji predstavljaju naslon i sedište.

Za modelovanje šipki koje predstavljaju oslonce stolice su upotrebljeni cilindri. Dva pravolinijska, postavljena paralelno i dva zakrivljena koja spajaju paralelne cilindre. Primenom opcije bend na cilindre koji treba da budu savijeni zadovoljeni su parametri koji se tiču vizuelnog kvaliteta modela. Svi delovi su na kraju spojeni u jedan segment opcijom Target Weld koja se zasniva na spajanju verteksa dva susedna cilindra.

Za izradu modela je potrebno malo vremena i ne zahteva se napredno poznavanje programa jer se zasniva na upotrebi jednostavnih opcija i modifajera pri čemu finalna geometrija zadovoljava ranije određene parametre (sl. 2). 


\subsubsection{NURBS modelovanje}

NURBS modelovanje se zasniva na iscrtavanju krive onog oblika kakvog je i geometrija modela koji želimo da dobijemo. Analizom uglednog primera (slika 1) može se zaključiti da je za ovaj model potrebno iscrtati dve krive, jednu za oslonac stolice i drugu za modelovanje naslona $i$ sedišta. Za modelovanje naslona i sedišta je potrebno isctati liniju pod određenim uglom koji je je potrebno zaobliti jednostavnom primenom opcije fillet da bi se dobila žljena forma. Debljina segmenta se dobija podešavanjem parametara iscrtane linije. Ovako dobijenom modelu je potrebno zaobliti ivice i izmodelovati udubljenja, stoga je neophodno podeliti ga na vertekse i edževe kojima će se manipulisati pri modelovanju.

Primenom opcije Turbo Smooth radi zaoblavanja modela dolazi do prevelikih deformacija. Najveći problem predstavljaju ivice modela kao i mesta njihovih sučeljavanja. Takođe efekat nije zadovoljavajuć ni kada se radi o delu modela koji predstavlja spoj naslona i sedišta jer ekstrudovani verteksi deluju kao rupe u materijalu. Rešenje za deformaciju modela kod ivica se može potražiti u umetanju dodatnih edževa između već postojećih kako bi efekat smooth bio blaži i ograničen, ali on za posledicu ima dodatno usložnjavanje modela što nije povoljno. Dalja obrada modela bi zahtevala dodatno usložnjavanje koje je uslovljeno performansama računara na kome se vrši rad i može stvoriti problem bagovanja i gašenja programa.

Pri modelovanju šipki, princip se takođe zasniva na iscrtavanju linije koja će predstavljati model, upotrebi opcije fillet za njeno zakrivljenje i zadavanjem određene debljine kako bi se dobio model. Zakrivljenje se dobija deljenjem jednog dela na vise manjih segmenata postavljenih pod različitim uglom kako bi se stvorio efekat polukružnog elementa, međutim ti segmenti su jasno vidljivi što ne doprinosi vizuelnom efektu i čini model nedovoljno dobrim za dalju obradu i prezentaciju.

Modelovanje ovom metodom zahteva naprednije poznavanje programa, oduzima vise vremena i može biti uslovljeno performansama računara. Takođe dolazi do velikih deformacija prilikom obrade modela uprkos njegovom dodatnom usložnjavanju, tako da za ovo istraživanje finalni rezultat ne daje željene performanse, kao što je prikazano na slici 3 .

\subsubsection{Uporedna analiza}

U tabeli 1 su prikazani osnovni parametri vrednovanja pristupa modelovanju gde je pokazano da je geometrijsko modelovanje $u$ dve kategorije znatno bolje (utrošeno vreme i finalna geometrija), dok se po broju verteksa poligona izdvaja NURBS modelovanje sa skoro tri puta manjim brojem.

Tabela 1. Analiza pristupa modelovanju u 3DS Max-u

\begin{tabular}{|c|c|c|c|}
\hline $\begin{array}{c}\text { Tehnika } \\
\text { modelovanja }\end{array}$ & Geometrija & Vreme & $\begin{array}{c}\text { Broj poligona i } \\
\text { verteksa }\end{array}$ \\
\hline $\begin{array}{c}\text { Polygon } \\
\text { modeling }\end{array}$ & $\begin{array}{c}\text { Zadovoljavajuća, } \\
\text { dobro prezentovanje } \\
\text { materijala }\end{array}$ & $\begin{array}{c}\text { Oko 2 } \\
\text { sata }\end{array}$ & $\begin{array}{c}\text { Vertex: 220906 } \\
\text { Polygon: 220904 }\end{array}$ \\
\hline $\begin{array}{c}\text { NURBS } \\
\text { modelovanje }\end{array}$ & $\begin{array}{c}\text { Deformisana i } \\
\text { izlomljena }\end{array}$ & $\begin{array}{c}\text { Oko 4 } \\
\text { sata }\end{array}$ & $\begin{array}{c}\text { Vertex: 71,290 } \\
\text { Polygon: } 142144\end{array}$ \\
\hline
\end{tabular}

Analizirajući sve parametre, sa posebnim osvrtom na vizuelni prikaz finalnih modela zaključuje se da je za ovo istraživanje pogodnije geometrijsko modelovanje.
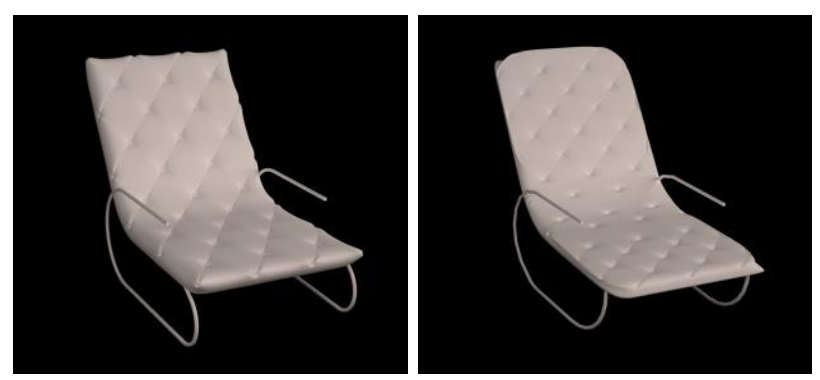

Slika 2 (levo). Model dobijen pomygon modelovanjem Slika 3 (desno). Model dobijen NURBS modelovanjem

\subsection{Modelovanje stolice korišćenjem Blendera}

U Blenderu su istraženi sledeći pristupi: modelovanje upotrebom geometrije, pri kome se osnovna geometrije oblikuje tako da se dobije željeni model i modelovanje paterna, pri čemu se kreće od manjih segmenata i nadovezivanjem na njih se dobija željeni model.

\subsubsection{Geometrijsko modelovanje}

Ovakav pristup modelovanju se zasniva na određivanju početnog geometrijskog tela koje daljom obradom daje željeni oblik modela. Početna geometrija u ovom slučaju je kubus od koga nastaju sedište i naslon stolice. Kada su utvrđene dimenzije modela pristupa se njegovom opblikovanju uz korišćenje verteksa i edževa. Da bi se stekao utisak mekog materijala potrebno je zaobliti oštre ivice modela. Za to je najpogodniji metod kombinovanja opcija bevel i subdivision surface. Kako se radi o usložnjavanju modela program i računar se dodatno opterećuju, što je u ovom konkretnom slučaju predstavljalo nesavladivu prepreku. Kada su podešavanja opcija na dovoljno dobrom nivou da se zadovolje utvrđeni parametri dolazi do bagovanja računara i program prestaje da radi, nakon čega sledi automatsko gašenje. Jedini način da se modelovanje dovede do kraja je drastično smanjenje performansi modela što ne zadovoljava parametre koji su određeni. Performanse računara na koje se ne može uticati uslovile su da model bude slabijeg kvaliteta i da izgleda nedovršeno i deformisano jer su vrednosti opcija kojima je obrađen drastično smanjene i nisu dale rezultate koji se od njih očekuju (slika 4).

Geometrijski pristup modelovanju šipki stolice nije dao značajno bolje rezultate. Princip se zasniva na modelovanju cilindara od kojih dva treba da budu zakrivljena, a sva četiri spojena u jednu celinu. Modelovanje pravolinijskih cilindara ne predstavlja nikakav problem, vrlo je jednostavno i daje zadovoljavajuće rezultate. U slučaju savijenih cilindara najpre se mora izvršiti podela na segmente, pri čemu broj podela uslovljen performansama računara kao što je bio slučaj pri modelovanju naslona i sedišta stolice. Mali broj podela uslovljava kvalitet modela koji nije zadovoljavajuć.

Ovim istraživanjem je ustanovljeno da je potrebno koristiti računar sa naprednijim performansama za dobijanje željenih rezultata. Metoda nije kompleksna, pogodna je za one koji nemaju napredno znanje iz ove oblasti, korišćene opcije su jednostavne za upotrebu, ali u konkretnom primeru modelovanje oduzima previse vremena, korišćeni softver nije dovoljno dobar i finalni model ne zadovoljava utvrđene parametre (slika 4). 


\subsubsection{Modelovanje pomoću paterna}

Pristup modelovanju se zasniva na određivanju malog segmenta modela - paterna, koji se modeluje. Jednom kada je dobijen željeni oblik parterna potrebno je umnožiti ga po vrstama i kolonama onoliko puta koliko je dovoljno da se napravi gornja strana naslona i sedišta stolice.

Za umnožavanje je pogodno koristiti opciju array koja daje mogućnost kontrolisanja parametara, kao što su udaljenost i ugao postavljanja kopije $u$ odnosu na originalan segment pri kopiranju po određenoj osi.

Kada se ovako dobijen model zaobli pomocu opcije subdivision surface mogu se pojaviti prvi problemi sa geometrijom ukoliko je propušteno da se prilikom umnožavanja svi delovi sklope u jednu celinu (murge). Posledice su najvidljivije u predelu uglova paterna jer je svaki od njih zaobljen zasebno pri čemu se stvaraju rupe $u$ modelu.

Rešenje ovog problema je naknadno primeniti opciju murge na vertekse koji se nalaze na uglovima četiri susedna paterna i spojiti ih u jedan. Značajna ušteda vremena se može obezbediti ukoliko se proces kopiranja ponovi i u opciji array odmah čekira polje murge, čime će svi segmenti biti automatski spojeni.

Tako dobijenom modelu je potrebno još odrediti debljinu opcijom extrude i saviti ga tako da se dobiju naslon $\mathrm{i}$ sedište stolice.

Pri modelovanju šipki potrebno je odrediti početnu geometriju i na njene fejseve primenjivati samo opcije extrude i rotate tako da se dobije oblik približan onom kome se teži. Finalni oblik se postiže opcijom subdivision surface koja daje fino zaobljen oblik šipke.

Ovaj pristup modelovanju nije kompleksan i postiže se odgovarajući finalni rezultat jer je uspešno prenet utisak o materijalu od koga bi stolica trebalo da bude izrađena i dobijena je željena geometrija modela (slika 5).

\subsubsection{Uporedna analiza}

U tabeli 2 su prikazani osnovni parametri vrednovanja pristupa modelovanju gde je pokazano da je geometrijsko modelovanje u Blenderu u dve kategorije znatno lošije od modelovana uz pomoć paterna (geometrija modela i vreme potrebno za izradu), dok je broj verteksa, poligona i triangulacije na strani geometrijskog modelovanja.

Tabela 2. Analiza pristupa modelovanju u Blenderu

\begin{tabular}{|c|c|c|c|}
\hline $\begin{array}{c}\text { Tehnika } \\
\text { modelovanja }\end{array}$ & Geometrija & Vreme & $\begin{array}{c}\text { Broj poligona i } \\
\text { verteksa }\end{array}$ \\
\hline $\begin{array}{c}\text { Modelovanje } \\
\text { uz pomoć } \\
\text { paterna }\end{array}$ & $\begin{array}{c}\text { Zadovoljavajuća, } \\
\text { dobro prezentovanje } \\
\text { materijala }\end{array}$ & $\begin{array}{c}\text { Oko 2 } \\
\text { sata }\end{array}$ & $\begin{array}{c}\text { Vertex: } 90616 \\
\text { Faces: } 89752 \\
\text { Triangles: } 179504\end{array}$ \\
\hline $\begin{array}{c}\text { Geometrijsko } \\
\text { modelovanje }\end{array}$ & $\begin{array}{c}\text { Deformisana i } \\
\text { izlomljena }\end{array}$ & $\begin{array}{c}\text { Oko 6 } \\
\text { sati }\end{array}$ & $\begin{array}{c}\text { Vertex: } 22217 \\
\text { Faces: } 21892 \\
\text { Triangles: } 43872\end{array}$ \\
\hline
\end{tabular}

To ne menja značajno činjenicu da uporednom analizom ovih modela na slikama 2 i 3 dolazi do utiska da je metoda modelovanja uz pomoć paterna za dato istraživanje pružila znatno bolje krajnje rezultate.
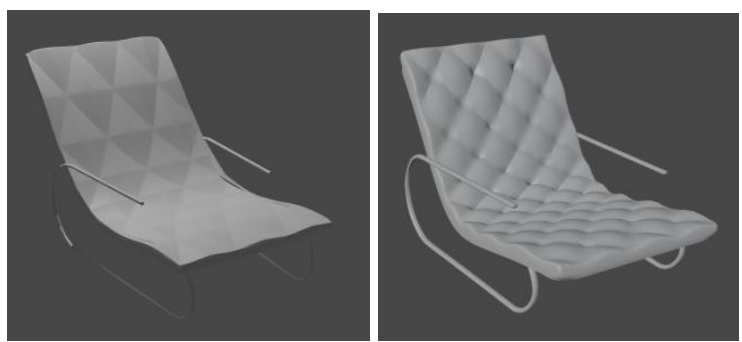

Slika 4 (levo). Model dobijen geometrijskim modelovanjem Slika 5 (desno). Model dobijen pomoću paterna

\section{OPTIMIZACIJA}

Optimizacija je neophodna jer veliki broj verteksa i edževa nije pogodan za dalju obradu modela i može dovesti do sporijeg rada programa i računara na kome se vrši modelovanje. Analiza uspešnosti metode se zasniva se na količini deformacija koje se javljaju i na odnosu broja verteksa i edževa pri početku i kraju procesa optimizacije - što su deformacije i brojevi verteksa i edževa na kraju procesa manji pristup je uspešniji.

\subsubsection{Optimizacija u 3DS Max-u}

Procesu optimizacije u 3DS Max-u se može pristupiti na vise načina. Jedna od prednosti ovog programa su modifajeri koji služe specijalno za optimizaciju.

Prva metoda koju program 3DS Max nudi jeste upotreba modifajera ProOptimizer koji na početku kalkuliše ukupan broj verteksa u modelu i zasniva se na smanjenju tog broja kako bi se obavio proces optimizacije. Proces optimizacije se svodi na ispitivanje vrednosti unetih $\mathrm{u}$ podešavanjima ovog modifajera . Ukoliko unete vrednosti dovode do prevelike deformacije modela rešenje se može potražiti u opciji smooth, pri čemu se dobijaju rezultati koji su neznatno lošiji od originala po pitanju geometrije. Opcija smooth donosi ponovno povećanje broja verteksa, ali je on i dalje manji od broja na originalnom modelu, dok je povećanje broja poligona drastičnije i dostiže broj veći od broja pri originalnom modelu (tabela 3).

Naredna metoda se zasniva na opciji Optimize uz pomoć koje program sam odredi broj verteksa potrebnih kako se geometrija ne bi deformisala, ostavljajući mogućnost da se te vrednosti promene ukoliko korisnik smatra da nisu dovoljno dobre. Deformacija geometije se manifestuje samo u delovima gde su napravljena udubljenja na segmentu koji čini naslon i sedište stolice, ali proces optimizacije je uspešan uzimajući u obzir drastično smanjivanje broja verteksa u modelu (tabela 3 ).

Tabela 3. Analiza pristupa optimizaciji u 3DS Max-u

\begin{tabular}{|c|c|c|}
\hline $\begin{array}{c}\text { Pristup } \\
\text { optimizaciji }\end{array}$ & Geometrija & $\begin{array}{c}\text { Broj poligona i } \\
\text { verteksa }\end{array}$ \\
\hline $\begin{array}{c}\text { Originalna } \\
\text { geometrija }\end{array}$ & $/$ & $\begin{array}{c}\text { Vertex: } 220906 \\
\text { Polygon: } 220904\end{array}$ \\
\hline $\begin{array}{c}\text { Modifajer } \\
\text { ProOptimizer }\end{array}$ & $\begin{array}{c}\text { Zadovoljavajuća, } \\
\text { dobra prezentacija } \\
\text { materijala }\end{array}$ & $\begin{array}{c}\text { Vertex: } 135000 \\
\text { Polygon: 269904 }\end{array}$ \\
\hline $\begin{array}{c}\text { Modifajer } \\
\text { Optimize }\end{array}$ & $\begin{array}{c}\text { Zadovoljavajuća, male } \\
\text { deformacije }\end{array}$ & $\begin{array}{c}\text { Vertex: } 49959 \\
\text { Polygon: } 99882\end{array}$ \\
\hline
\end{tabular}




\subsubsection{Optimizacija u Blenderu}

U sklopu modifajera Decimate se nalaze dve opcije koje mogu zadovoljiti potrebu optimizacije i koje su predmet istraživanja.

Opcija Edge collapsing se zasniva na podešavanju slajdera čija se vrednost kreće od nule do jedinice.

Jedinica u ovom slučaju označava originalnu geometriju dok nula predstavlja apsolutno uprošćenu geometriju koja je deformisana. Princip rada zasniva se na traženju vrednosti koja će optimizovati model bez deformisanja. Pri optimizovanom modelu čiji je broj verteksa i edževa smanjen za 50\% rezultat je zadovoljavajućeg kvaliteta u odnosu na utvrđene parametre. Prilikom većeg zumiranja mogu se uočiti nedostaci u geometriji modela ali je on pogodan za prezentaciju.

Sledeća ispitana opcija je Iteration count. Pri njenom korišćenju se poništava efekat opcije subdivide kojom je dobijena fino oblikovana geometrija modela. Program na osnovu unetog parametra vrši proračun i zatim uklanja edževe koje smatra nepotrbenim a fejseve koje je ukinuti edž razdvajao spaja u jedan. Kao rezultat optimizacije dobijen je model čija je geometrija deformisana u odnosu na originalnu. Segment stolice koji se odnosi na naslon i sedište je uprošćen do te mere da fino zaobljenje više ne postoji, narušavajući time prikaz materijala modela.

Tabela 4. Analiza pristupa optimizaciji u Blenderu

\begin{tabular}{|c|c|c|}
\hline $\begin{array}{c}\text { Pristup } \\
\text { optimizaciji }\end{array}$ & Geometrija & $\begin{array}{c}\text { Broj poligona i } \\
\text { verteksa }\end{array}$ \\
\hline $\begin{array}{c}\text { Originalna } \\
\text { geometrija }\end{array}$ & $/$ & $\begin{array}{c}\text { Vertex: } 90616 \\
\text { Faces:89752 } \\
\text { Triangles: } 179504\end{array}$ \\
\hline $\begin{array}{c}\text { Opcija } \\
\text { Edge collapsing }\end{array}$ & $\begin{array}{c}\text { Zadovoljavajuća, dobro } \\
\text { prezentovanje materijala }\end{array}$ & $\begin{array}{c}\text { Vertex: } 21252 \\
\text { Faces: } 41415 \\
\text { Triangles: } 41415\end{array}$ \\
\hline $\begin{array}{c}\text { Opcija } \\
\text { Iteration count }\end{array}$ & $\begin{array}{c}\text { Nije zadovoljavajuća, } \\
\text { gubi se utisak o materijalu }\end{array}$ & $\begin{array}{c}\text { Vertex: 22882 } \\
\text { Faces: 22526 } \\
\text { Triangles: 44969 }\end{array}$ \\
\hline
\end{tabular}

U tabeli 4 su sumirane vrednosti dobijenih optimizovanih modela. Postizanjem sličnog broja verteksa, fejseva i triangulacija pri optimizaciji oba modela zaključeno je da je pogodnija opcija Edge collapsing. Ova opcija omogućava značajno smanjenje pomenutih parametara a da pritom čuva originalnu geometriju. Druga opcija - Iteration count je dobra za očuvanje oblika modela ali se njene performanse pri smanjenju broja verteksa u modelu nisu pokazale zadovoljavajućim.

\section{ZAKLJUČAK}

Zaključak o pristupu modelovanju primerenijem za finalnu prezentaciju zasniva se na vizuelnom utisku koji clay modeli ostavljaju. Parametri koji se tiču vremena utrošenog na izradu i optimizaciju modela kao i njihove kompleksnosti su približno jednaki i ni jedan pristup se ne izdvaja značajnije.
Model dobijen korišćenjem 3DS Max-a nakon optimizacije ima duplo veći broj verteksa od modela dobijenog upotrebom Blendera. Međutim uporednom analizom finalnih modela dobijenih korišćenjem pomenutog softvera primetna je razlika u kvalitetu. Pri modelovanju u 3DS Max-u dobijena su ujednačenija udubljenja na segmentu sedišta i naslona, ivice su finije zaobljene, ne dolazi do deformacija i materijal je verodostojnije prikazan.

Uspešnost prezentacije je ranije definisana i zasniva se na kvalitetu i realističnom prikazu modela. Na osnovu prethodnih analiza zaključak je da više utvrđenih parametara za ovo istraživanje zadovoljava finalni model iz 3DS Max-a kao i da je kvalitet tog finalnog modela povoljniji za prezentaciju, bilo da se radi o renderu ili internet prezentaciji.

\section{LITERATURA}

[1] https://www.blender.org/features/modeling/ (pristupljeno u avgustu 2019.)

[2] https://all3dp.com/2/blender-how-to-reduce-polygons/ (pristupljeno u avgustu 2019.)

[3] https://area.autodesk.com/tutorials/3ds-max-modelingtechniques-modeling-with-splines/ (pristupljeno $\mathrm{u}$ avgustu 2019.)

[4] https://www.katsbits.com/tutorials/blender/basicoptimise-models-for-export-to-games.php (pristupljeno u avgustu 2019.)

[5] http://www.diva-portal.org/smash/get/diva2:638944/FULLTEXT02 (pristupljeno u avgustu 2019.)

[6] https://knowledge.autodesk.com/support/3ds-max/learn-explore (pristuplljeno u avgustu 2019.)

[7] https://www.wayfair.ca/furniture/ (pristupljeno u avgustu 2019)

\section{Kratka biografija:}

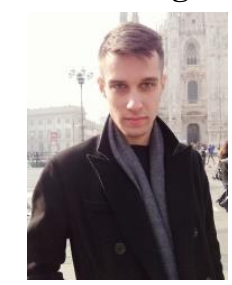

Radiša Pavićević rođen je u Kragujevcu 1995. god. Master rad na Fakultetu tehničkih nauka iz oblasti arhitekture uporedna analiza pristupa 3D modelovanju i optimizaciji modela nameštaja . kontakt: radisapavicevic74@gmail.com 